\title{
PERANCANGAN SISTEM PEMBELAJARAN DARING MENGGUNAKAN FRAMEWORK CODEIGNITER (CI) DI PAUD FLAMBOYAN JAKARTA
}

\author{
Dinda Yadini ${ }^{1}$, Verdi Yasin ${ }^{2}$, Anton Zulkarnain Sianipar ${ }^{3}$ \\ Prodi Sistem Informasi, Departemen Teknik Informatika, Departemen Teknik Informatika \\ STMIK Jayakarta ${ }^{1,2,3}$ \\ e-mail: dindayadini1@gmail.com, verdiyasin29@gmail.com, antonz.jayakarta@gmail.com
}

Received: 2021-02-20, Revised: 2021-03-25, Accepted: 2021-03-30

\begin{abstract}
Abstrak
PAUD flamboyan merupakan salah satu PAUD yang ada di kota Jakarta Pusat. PAUD flamboyan telah menggunakan sistem pembelajaran daring namun belum dimanfaatkan dengan maksimal karena hanya sebatas menggunggah soal dan belum ada fasilitas video yang mengilustrasikan suatu bahasan materi pembelajaran. Hal tersebut mengakibatkan kurangnya minat siswa dan guru untuk memanfaatkan sistem pembelajaran daring. Tujuan dari penelitian ini yaitu membuat sistem pembelajaran daring untuk PAUD flamboyan dimana pemberian materi dan pengumpulan tugas dapat dilakukakn secara efektif sehingga pembelajaran daring akan berjalan dengan maksimal. Untuk perancangan sistem pembelajaran daring ini metode yang digunakan untuk pengumpulan data yaitu observasi, wawancara, dan studi kepustakaan. Metode perancangan aplikasi yang digunakan pada penelitian ini adalah metode Waterfall dan Unified Modeling Language (UML). Teknik pengujian yang digunakan penulis yaitu pengujian Black Box. Hasil dari penelitian ini adalah sistem pembelajaran daring yang terkomputerisasi sehingga dapat menghasilkan sistem pembelajaran daring yang efektif dan efisen.
\end{abstract}

Kata kunci: Perancangan, Sistem, CodeIgniter

Abstract: The flamboyant PAUD is one of the PAUD in Central Jakarta. The flamboyant PAUD has used an online learning system but has not been fully utilized because it is only limited to uploading questions and there is no video facility that illustrates a discussion of learning material. This results in a lack of interest from students and teachers to take advantage of the online learning system. The purpose of this research is to create an online learning system for flamboyant PAUD where the provision of materials and collection of assignments can be carried out effectively so that online learning will run optimally. For the design of this online learning system, the methods used for data collection are observation, interviews, and literature study. The application design method used in this research is the Waterfall method and the Unified Modeling Language (UML). The testing technique used by the author is Black Box testing. The result of this research is a computerized online learning system so that it can produce an effective and efficient online learning system.

Keywords: Desain, System, CodeIgniter 
https://jurnal.amikwidyaloka.ac.id/index.php/awl

jurnal@amikwidyaloka.ac.id / editor.jurnalwidya@gmail.com

\section{Pendahuluan (or Introduction)}

PAUD flamboyan merupakan salah satu PAUD yang ada di kota Jakarta Pusat. PAUD flamboyan telah menggunakan sistem pembelajaran daring untuk mendukung pembelajaran tatap muka di kelas. Saat ini penggunaan sistem pembelajaran daring di PAUD flamboyan hanya sebatas menggunggah soal. Selain masalah diatas ada hal lain yang menyebabkan siswa dan guru belum memanfaatkan sistem pembelajaran daring diantaranya adalah tampilan yang kurang menarik dan belum ada fasilitas video yang mengilustrasikan suatu bahasan materi pembelajaran. Hal tersebut mengakibatkan kurangnya minat siswa dan guru untuk memanfaatkan sistem pembelajaran daring. Berdasarkan hasil wawancara dengan Ibu Caca selaku kepala sekolah PAUD flamboyan Jakarta, sistem pembelajaran daring telah ada sejak awal pandemi pada bulan maret 2020, hingga saat ini merasakan banyak manfaat. Dengan sistem pembelajaran daring, siswa dapat mengakses materi pembelajaran, mengerjakan tugas dan ujian, kapan saja dan dimana saja. Bagi guru, sistem pembelajaran daring memberikan banyak manfaat dan kemudahan dalam penyampaian bahan belajar.

Berdasarkan penelitian Perancangan dan implementasi e-learning berbasis web pada SMA Negeri 1 Siantar (Hutagalung et al., 2019) dan perancangan sistem e-learning berbasis web pada SMP N 2 Busalangga (Jimi, 2020) penulis banyak mengambil referensi sebagai penunjang pembuatan jurnal ini. Pada kedua jurnal referensi tersebut membahas tentang teknologi informasi e-learning yang mampu menyediakan bahan ajar sebagai informasi antara siswa dan pengajar untuk sumber belajar dan sarana evaluasi pembelajaran.

Berdasarkan permasalahan yang dihadapi, PAUD flamboyan membutuhkan sebuah sistem pembelajaran daring yang dapat menunjang pembelajaran di luar sekolah dimana sistem pemberian materi dan media pengumpulan tugas dapat dilakukakn secara efektif dan dapat diakses kapanpun dan dimana pun sehingga akan memaksimalkan pemberian materi yang dibutuhkan. Selain itu, sekolah membutuhkan media yang dapat mengatasi keterbatasan waktu dalam interaksi antara guru dengan murid.

Jenis penelitian ini adalah deskriptif kualitatif yaitu memahami kondisi yang terjadi. Metode pengumpulan data yaitu observasi, wawancara, dan studi kepustakaan. Metode perancangan aplikasi yang digunakan pada penelitian ini adalah metode Waterfall dan Unified Modeling Language (UML). Teknik pengujian yang digunakan penulis yaitu pengujian Black Box.

\section{Tinjauan Literatur (or Literature Review)}

Endah Wiji Lestari, Nurfitri Yani menjelaskan sistem pembelajaran online yang dibangun dapat membantu pembelajaran yang dilakukan tidak hanya di dalam kelas atau labolatorium melainkan dapat dilakukan dimanapun dan kapanpun melalui media internet secara online, dapat meningkatkan efektifitas Guru dalam memberikan berkas materi dan soal-soal latihan kepada siswa secara online menggunakan jaringan internet dalam rangka memanfaatkan teknologi informasi, Sistem pembelajaran online menjadi salah satu alternatif dalam meningkatkan minat belajar siswa dalam memanfaatkan media internet.

Made Pradnyana Ambara menjelaskan pengembangan sistem informasi elearning menggunakan framework codeigniter yang diterapkan pada lembaga pendidikan SMK TI di Bali yang diuji menggunakan metode black box testing $100 \%$ sesuai dan bekerja dengan baik sesuai fungsinya. Sistem elearning ini memiliki beberapa fitur yang sangat membantu para guru dan siswa didalam proses pembelajaran seperti informasi jadwal pelajaran, pemberian materi, tugas atau ujian, kelola abensi serta media komunikasi chatting online. Sistem ini memiliki interface yang responsive, sehingga sistem elearning nyaman dibuka diberbagai perangkat dengan ukuran layar yang berbeda 


\section{Metode Penelitian (or Research Method)}

\subsection{Metode Pengumpulan Data}

Metode pengumpulan data yang digunakan dalam penelitian ini adalah sebagai berikut :

a. Studi pustaka, Teknik pengumpulan data dilakukan dengan cara mempelajari dalam bentuk literature, buku, internet dan sumber tertulis lainnya yang berkaitan atau berhubungan dengan judul penelitian.

b. Observasi, Teknik pengumpulan data dilakukan dengan cara pengamatan di PAUD Flamboyan Jakarta hal itu dilakukan dengan maksud untuk mendapatkan data dan dokumen secara langsung yang benar-benar terjadi didalam pelaksanaan atau penelitian.

c. Wawancara, Teknik pengumpulan data dilakukan dengan cara tanya jawab dengan yang bersangkutan dan yang berwenang untuk memperoleh data informaasi yang diperlukan dan mengetahui alur pembelajaran pada PAUD Flmaboyan Jakarta.

d. Dokumentasi, merupakan kegiatan pengumpulan informasi atau data yang berdasarkan hasil dari catatan. Dokumentasi dapat berupa bahan tertulis atau foto yang dipersiapkan secara tidak sengaja oleh peneliti seperti penggunaan kamera untuk mengabadikan kegiatan wawancara sebagai dokumentasi

\subsection{Analisa kebutuhan Sistem}

a. Analisis Kebutuhan Fungsional

Kebutuhan fungsional adalah kebutuhan yang berisi proses atau layanan dalam aplikasi yang nantinya harus disediakan oleh sistem, diantaranya adalah sebagai berikut :

1) Sistem mampu membagikan materi pelajaran daring dan tugas secara cepat dan tepat.

2) Sistem dapat menerima materi pelajaran dan mengerjalan tugas dengan cepat dan tepat.

3) Sistem dapat mengetahui nilai tugas yang telah dikerjakan murid.

4) Sistem dapat memberikan laporan nilai tugas semua murid.

b. Analisis Kebutuhan Non Fungsional

Analisis kebutuhan non fungsional dapat digunakan sebagai suatu bentuk kebutuhan berupa perangkat yang dibutuhkan sistem dan dapat terbagi dalam hal untuk pengembangan dan penggunaanya.

\subsection{Analisis Kebutuhan Operasional}

a. Sumber Daya Manusia

Seorang administrator untuk mengelola aplikasi, guru dan murid.

b. Infrastruktur Pendukung

1) Lokasi yang aman untuk menempatkan komputer beserta saluran listrik untuk menyalakan komputer.

2) Kertas dan tinta untuk mencetak laporan nilai siswa.

\subsection{Analisis Sistem Yang Berjalan}

Dalam Analisis sistem yang berjalan menggunakan pemodelan proses untuk mengilustrasikan aktivitas-aktivitas yang dilakukan dan bagaimana data berpindah diantara aktivitas-aktivitas tersebut. Cara untuk merepresentasikan proses model dengan menggunakan UML(Unified Modeling Language) yaitu dengan Flowchart, Use Case Diagram, dan Activity Diagram.

\subsection{Teknik Analisis Data}

Teknik analisis data yang digunakan dalam penelitian ini adalah analisis SWOT. Analisis ini menganalisa tentang bagaimana melihat gabungan antara pemanfaatan kekuatan untuk menagkap 
peluang, mengatasi kelemahan, dengan mengambil kesempatan, menggunakan kekuatan untuk menghindari ancaman, meminimalkan kelemahan dan menghindarkan ancaman.

\section{Hasil dan Pembahasan (or Results and Analysis)}

\subsection{Flowchart}

Proses pembelajaran daring yang diusulkan pada PAUD Flmaboyan Jakarta menggunakan flowchart sebagai berikut :

Gambar 1 Flowchart Sistem Yang Diusulkan

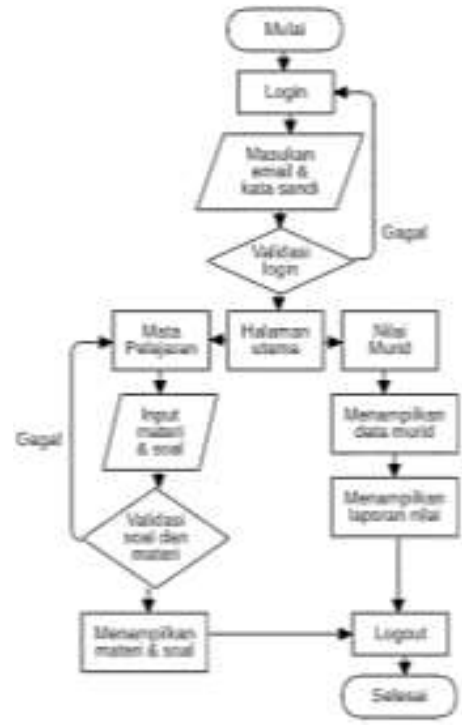

Adapun penjelasan dari gambar tersebut sebagai berikut :

a. Guru melakukan login

b. Kemudian akan divalidasi, jika login gagal proses tidak berlanjut dan akan melakukan login kembali, jika login berhasil akan masuk ke halaman utama.

c. Pada menu nilai murid, guru bisa melihat laporan nilai seluruh siswa dan bisa melakukan cetak laporan nilai dan cetak laporan prestasi.

d. Pada menu mata pelajaran, guru berfungsi untuk input materi pelajaran dan soal jika input gagal maka proses tidak berlanjut dan akan melakukan input kembali, jika input berhasil soal dan materi akan ditampilkan.

\subsection{Use Case Diagram}

Gambar 2 Use Case Diagram Sistem Yang Diusulkan

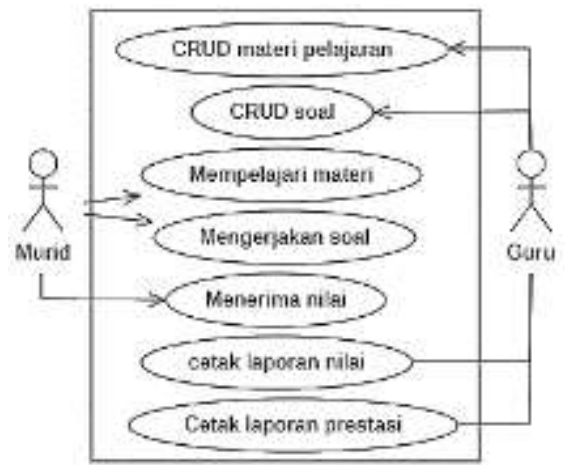


Berikut adalah pendefinisian use case diagram pada sistem pembelajaran daring di PAUD Flamboyan Jakarta:

Tabel 1 Pendefinisian Use Case Diagram

\begin{tabular}{|c|c|l|}
\hline No & Use case & \multicolumn{1}{|c|}{ Deskripsi } \\
\hline 1 & CRUD materi pelajaran & $\begin{array}{l}\text { Merupakan proses untuk membuat, membaca, mengubah, dan } \\
\text { menghapus materi pelajaran yang dilakukan oleh guru. }\end{array}$ \\
\hline 2 & CRUD soal & $\begin{array}{l}\text { Merupakan proses untuk membuat, membaca, mengubah, dan } \\
\text { menghapus soal yang dilakukan oleh guru. }\end{array}$ \\
\hline 3 & Mempelajari materi & $\begin{array}{l}\text { Merupakan proses mempelajari materi yang dilakukan oleh } \\
\text { murid. }\end{array}$ \\
\hline 4 & Mengerjakan soal & Merupakan proses mengerjakan soal yang dilakukan oleh murid. \\
\hline 5 & Menerima nilai & $\begin{array}{l}\text { Merupakan proses untuk menerima nilai setelah mengerjakan } \\
\text { soal yang dilakukan oleh murid. }\end{array}$ \\
\hline 6 & Cetak laporan nilai & $\begin{array}{l}\text { Merupakan proses untuk mencetak laporan nilai murid yang } \\
\text { dilakukan oleh guru yang akan diberikan kepada masing-masing } \\
\text { murid yang dilakukan oleh guru. }\end{array}$ \\
\hline 7 & Cetak laporam prestasi & $\begin{array}{l}\text { Merupakan proses untuk mencetak laporan nilai murid yang } \\
\text { dilakukan oleh guru. }\end{array}$ \\
\hline
\end{tabular}

\subsection{Activity Diagram}

Gambar 3 Activity Diagram Sistem Yang Diusulkan

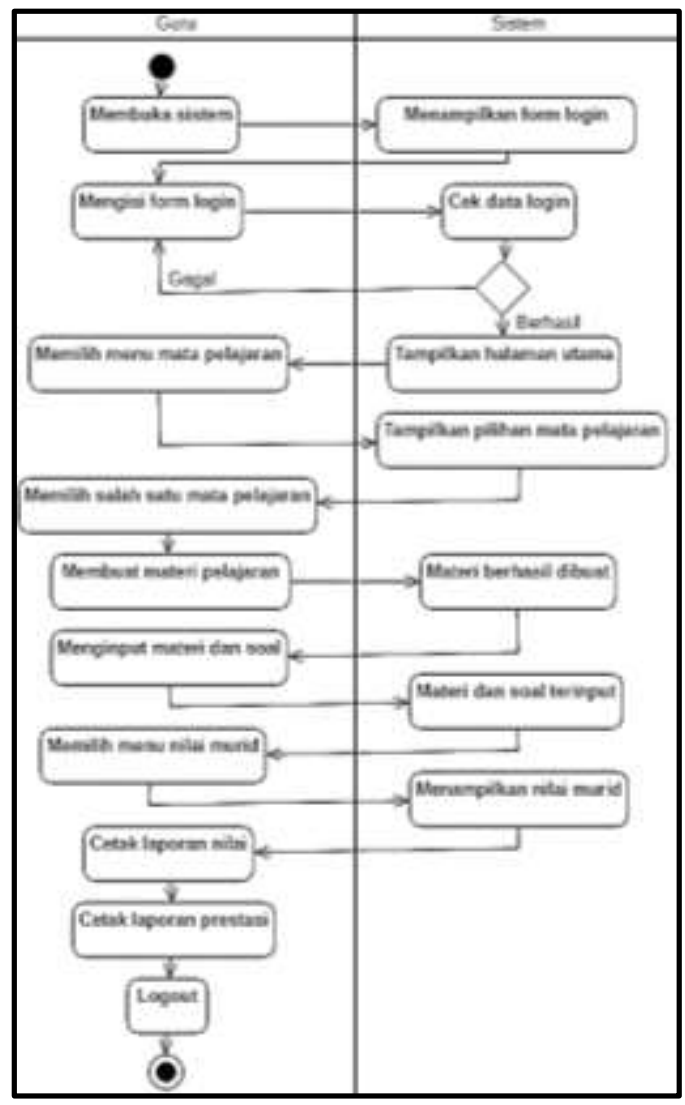

Adapun penjelasan dari gambar tersebut sebagai berikut :

a. 1 initial node, sebagai objek yang diawali. 
b. 17 action, sistem yang mendeskripsikan eksekusi dari aksi yaitu melakukan membuka sistem (guru), menampilkan form login (sistem), mengisi form login (guru), cek data login (sistem), tampilkan halaman utama (sistem), memilih menu mata pelajaran (guru), tampilkan pilihan mata pelajaran (sistem), memilih salah satu mata pelajaran (guru), membuat materi pelajaran (guru), materi berhasil dibuat (sistem), menginput materi dan soal (guru), materi dan soal terinput (sistem), memilih menu nilai murid (guru), cetak laporan nilai (guru), cetak laporan prestasi (guru), logout (guru).

c. Decision digunakan untuk menggambarkan suatu keputusan atau tindakan yang harus diambil pada kondisi tertentu.

d. 1 final state, sebagai objek yang di akhiri.

\subsection{Perancangan Basis Data}

Desain basis data menjelaskan nama tabel, tipe file, media penyimpanan yang digunakan, primary key, panjang record, dll. Spesifikasi basis data yang digunakan dalam sistem yang akan dibangun adalah sebagai berikut:

a. Perancangan tabel guru

Nama tabel : guru

Media : : Hardisk

Primary Key: id_guru

Tabel 2 Desain Tabel Guru

\begin{tabular}{|c|c|c|c|}
\hline Nama Field & Type & Values & Index \\
\hline id_guru & Int & 11 & Primary Key \\
\hline nik & Varchar & 20 & \\
\hline nama & Varchar & 100 & \\
\hline Email & Varchar & 100 & \\
\hline password & Varchar & 100 & \\
\hline
\end{tabular}

b. Perancangan tabel jawaban

Nama tabel : jawaban

Media : Hardisk

Primary Key: id_jawaban

Tabel 3 Desain Tabel Jawaban

\begin{tabular}{|c|c|c|c|}
\hline Nama Field & Type & Values & Index \\
\hline id_jawaban & Int & 11 & Primary Key \\
\hline id_soal & Int & 11 & Foreign key \\
\hline jawaban & Varchar & 255 & \\
\hline status & Enum & Benar, salah & \\
\hline
\end{tabular}

c. Perancangan tabel kelas

Nama tabel : kelas

Media : Hardisk

Primary Key: id_kelas

Tabel 4 Desain Tabel Kelas

\begin{tabular}{|c|c|c|c|}
\hline Nama Field & Type & Values & Index \\
\hline id_kelas & Int & 11 & Primary Key \\
\hline kelas & Char & 1 & \\
\hline
\end{tabular}

d. Perancangan tabel mapel

Nama tabel : mapel 
Media : Hardisk

Primary Key: id

Tabel 5 Desain Tabel Mapel

\begin{tabular}{|c|c|c|c|}
\hline Nama Field & Type & Values & Index \\
\hline id & Int & 11 & Primary Key \\
\hline nama_mapel & Varchar & 100 & \\
\hline
\end{tabular}

e. Perancangan tabel materi

Nama tabel : materi

Media

: Hardisk

Primary Key: id

Tabel 6 Desain Tabel Mapel

\begin{tabular}{|c|c|c|c|}
\hline Nama Field & Type & Values & Index \\
\hline id & Int & 11 & Primary Key \\
\hline id_mapel & Int & 11 & Foreign key \\
\hline nama_materi & Varchar & 100 & \\
\hline foto & Varchar & 255 & \\
\hline video & Varchar & 100 & \\
\hline semester & Enum & ganjil, genap & \\
\hline
\end{tabular}

f. Perancangan tabel nilai

Nama tabel : nilai

Media : Hardisk

Primary Key: id

Tabel 7 Desain Tabel Mapel

\begin{tabular}{|c|c|c|c|}
\hline Nama Field & Type & Values & Index \\
\hline Id & Int & 11 & Primary Key \\
\hline id_user & Int & 11 & Foreign key \\
\hline id_materi & Int & 11 & Foreign key \\
\hline Nilai & Int & 11 & \\
\hline
\end{tabular}

g. Perancangan tabel soal

Nama tabel : soal

Media : Hardisk

Primary Key : id

Tabel 8 Desain Tabel Soal

\begin{tabular}{|c|c|c|c|}
\hline Nama Field & Type & Values & Index \\
\hline id & Int & 11 & Primary Key \\
\hline id_materi & Int & 11 & Foreign key \\
\hline soal & longblob & & \\
\hline a & Varchar & 150 & \\
\hline b & Varchar & 150 & \\
\hline c & Varchar & 150 & \\
\hline d & Varchar & 150 & \\
\hline kunci & Enum & A, B, C, D & \\
\hline
\end{tabular}


h.Perancangan tabel user

Nama tabel : user

Media : Hardisk

Primary Key: id_user

Tabel 9 Desain Tabel User

\begin{tabular}{|c|c|c|c|}
\hline Nama Field & Type & Values & Index \\
\hline Id_user & Int & 11 & Primary Key \\
\hline nama & Varchar & 100 & \\
\hline nik & Int & 255 & \\
\hline tempat_lahir & Varchar & 255 & \\
\hline tanggal_lahir & Date & & \\
\hline alamat & Varchar & 255 & \\
\hline kelamin & Enum & Pria, wanita & \\
\hline nama_wali & Varchar & 255 & \\
\hline email & Varchar & 100 & \\
\hline no_hp & Varchar & 14 & \\
\hline password & Varchar & 100 & \\
\hline created_at & Date & & \\
\hline
\end{tabular}

\subsection{Implementasi Sistem}

Gambar 4 Implementasi Halaman Login User Guru

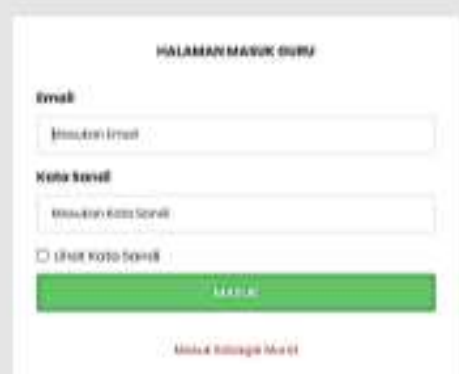

Keterangan Gambar:

Untuk menjalankan aplikasi pembelajaran daring berbasis web pada PAUD Flamboyan Jakarta user guru maupun murid harus melakukan login, memasukan email dan kata sandi yang telah dibuat.

Gambar 5 Implementasi Halaman Utama 
https://jurnal.amikwidyaloka.ac.id/index.php/awl

jurnal@amikwidyaloka.ac.id / editor.jurnalwidya@gmail.com

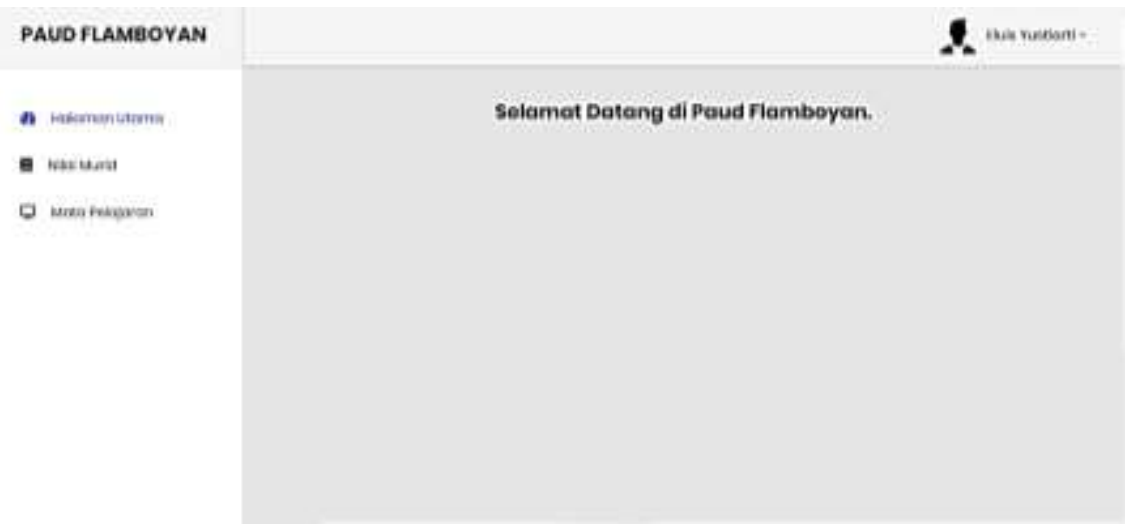

Keterangan Gambar:

Halaman utama ini muncul setelah user guru dan murid meng-input email dan kata sandi.

\section{Kesimpulan (or Conclusion)}

Berdasarkan dari penelitian yang telah dilaksanakan mengenai Perancangan Sistem Pembelajaran Daring Menggunakan Framework Codeigniter (CI) di PAUD Flamboyan Jakarta, maka dapat diambil kesimpulan sistem pembelajaran daring yang diusulkan dapat membantu guru dan siswa lebih maksimal dalam pembelajaran seperti guru lebih mudah untuk menambah materi beserta soal dan mencetak laporan nilai beserta laporan prestasi. Sedangkan murid bisa menerima materi beserta mengisi jawaban dan melihat langsung nilainya, Setelah adanya sistem pembelajaran daring yang diusulkan interaksi antara guru dan murid tidak monoton dan menambah minat belajar mengajar, sistem pembelajaran daring yang diusulkan menjadi lebih menarik dan menyenangkan. sistem pembelajaran daring yang diusulkan pembelajaran menjadi interaktif karena sudah dilengkapi dengan video untuk memperjelas materi.

\section{REFERENSI}

[1] Ambara, M. P. (2020). Pengembangan Sistem Informasi E-Learning Mendukung Proses Pembelajaran Jarak Jauh. Jurnal Ilmiah Pendidikan Citra Bakti, 7(2), 137-148. https://doi.org/10.38048/jipcb.v7i2.95

[2] Endah Wiji Lestari1, N. Y. (2019). Perancangan Pembelajaran Daring SMK PGRI 1 Jakarta. Paradigma: Jurnal Komputer Dan Informatika Universitas Bina Sarana Informatika, 21(2), 143-148. https://doi.org/10.31294/p.v20i2

[3] Hutagalung, J., Winata, H., \& Jaya, H. (2019). Perancangan Dan Implementasi E-Learning Berbasis Web Pada SMA Negeri 1 Siantar. Jurnal Teknologi Sistem Informasi Dan Sistem Komputer TGD, Vol 2,No 1(1), 7. https://ojs.trigunadharma.ac.id/index.php/jsk/article/view/90

[4] Jimi, A. (2020). Perancangan Sistem E-Learning Berbasis Web Pada Smp N 2 Busalangga. Jurnal Pendidikan Teknologi Informasi (JUKANTI), 3(1), 29-37. https://doi.org/10.37792/jukanti.v3i1.108

[5] Benni Triyono, Sri Purwanti, Verdi Yasin (2017) "Rekayasa Perangkat Lunak Sistem Informasi Pengiriman Dan Penerimaan Surat Atau Paket Berbasis Web", Journal of Information System, Applied, Management, Accounting and Research, e-ISSN: 2598-8719. p-ISSN: 2598-8700.Vol.1 No.1 (30 Desember 2017) p46-53 http://iournal.stmikjayakarta.ac.id/index.php/iisamar/article/view/12

[6] Julinda Maya Paramudita, Verdi Yasin (2019) "Perancangan Aplikasi Sistem Penyewaan Alat Berat (studi kasus: PT. Jaya Alam Sarana Jakarta) “, Journal of Information System, Applied, Management, Accounting and Research, e-ISSN: 2598-8719. p-ISSN: 2598-8700.Vol.3 No.1 (20 Februari 2019) p2329 http://journal.stmikjayakarta.ac.id/index.php/iisamar/article/view/73 
https://jurnal.amikwidyaloka.ac.id/index.php/awl jurnal@amikwidyaloka.ac.id / editor.jurnalwidya@gmail.com

[7] Muryan Awaludin, Verdi Yasin (2020) “Application Of Oriented Fast And Rotated Brief (Orb) And Bruteforce Hamming In Library Opencv For Classification Of Plants”, Journal of Information System, Applied, Management, Accounting and Research, e-ISSN: 2598-8719. p-ISSN: 2598-8700.Vol.4 No.3 (14 Agustus 2020) p51-59 http://journal.stmikjayakarta.ac.id/index.php/iisamar/article/view/247

[8] Ifan Junaedi, Dimas Abdillah, Verdi Yasin (2020) "Analisis Perancangan Dan Pembangunan Aplikasi Business Intelligence Penerimaan Negara Bukan Pajak Kementerian Keuangan RI”, Journal of Information System, Applied, Management, Accounting and Research, e-ISSN: 2598-8719. p-ISSN: 2598-8700.Vol.4 No.3 (14 Agustus 2020) p88-101 http://journal.stmikjayakarta.ac.id/index.php/jisamar/article/view/249

[9] Verdi Yasin (2012) 'Rekayasa Perangkat Lunak Berorientasi Objek”, Penerbit: Mitra Wacana Media, JakartaIndonesia.

[10] Anis Rohmadi, Verdi Yasin (2020) “Desain Dan Penerapan Website Tata Kelola Percetakan Pada CV Apicdesign Kreasindo Jakarta Dengan Metode Prototyping", Journal of Information System, Informatics and Computing. E-ISSN: 2597-3673 (Online), P-ISSN: 2579-5201 (Print) Vol. 4 No.1, June 22, 2020. Pp.70-85 http://journal.stmikjayakarta.ac.id/index.php/jisicom/article/view/210

[11] Septian Cahyadi, Verdi Yasin, Mohammad Narji, Anton Zulkarnain Sianipar (2020) "Perancangan Sistem Informasi Pengiriman Dan Penerimaan Soal Ujian Berbasis Web ( Studi Kasus: Fakultas Komputer Universitas Bung Karno)", Journal of Information System, Informatics and Computing. E-ISSN: $2597-$ 3673 (Online), P-ISSN: 2579-5201 (Print) Vol. 4 No.1, June 22, 2020. Pp.1-16 http://journal.stmikjayakarta.ac.id/index.php/jisicom/article/view/199

[12] Ifan Junaedi, Ndaru Nuswantari, Verdi Yasin (2019) “Perancangan Dan Implementasi Algoritma C4.5 Untuk Data Mining Analisis Tingkat Risiko Kematian Neonatum Pada Bayi”, Journal of Information System, Informatics and Computing. E-ISSN: 2597-3673 (Online), P-ISSN: 2579-5201 (Print) Vol. 3 No.1, February 13, 2019. Pp.29-44. http://journal.stmikjayakarta.ac.id/index.php/jisicom/article/view/203

[13] Verdi Yasin, Anindra Ramdhan Nugraha, Muhammad Zarlis, Ifan Junaedi (2018) "Smart System Of Fast Internet Access Development Using Backbone Network Method", Journal of Information System, Informatics and Computing. E-ISSN: 2597-3673 (Online), P-ISSN: 2579-5201 (Print) Vol. 2 No. 2, December 31, 2018. Pp.26-34. http://journal.stmikjayakarta.ac.id/index.php/jisicom/article/view/198

[14] Ito Riris Immasari, Verdi Yasin (2019) "Penggunaan Metode Analytic Hierarchy Process Untuk Menganalisis Faktor-Faktor Yang Mempengaruhi Pemilihan Calon Legislatif Di Dprd li Kota Tangerang", Journal of Information System, Informatics and Computing. E-ISSN: 2597-3673 (Online), P-ISSN: 2579-5201 (Print) Vol. 3 No. 2, December 10, 2019. Pp.53-58. http://journal.stmikjayakarta.ac.id/index.php/jisicom/article/view/139

[15] Verdi Yasin, Muhammad Zarlis, Tulus, Erna Budhiarti Nababan, Poltak Sihombing (2019) "Rancangan Miniatur Otomatisasi Bel Listrik Pada Gerbang Pintu Menggunakan Microkontroler Atmega8535", Journal of Information System, Informatics and Computing. E-ISSN: 2597-3673 (Online), P-ISSN: 2579-5201 (Print) Vol. 3 No. 1, February 13, 2019. Pp.13-20 http://journal.stmikjayakarta.ac.id/index.php/jisicom/article/view/68

[16] Anggeri S. Nurjaman, Verdi Yasin (2020) "Konsep Desain Aplikasi Sistem Manajemen Kepegawaian Berbasis Web Pada PT. Bintang Komunikasi Utama ”, Journal of Information System, Informatics and Computing. E-ISSN: 2597-3673 (Online), P-ISSN: 2579-5201 (Print) Vol. 4 No. 2, December 28, 2020. Pp.143-174 http://journal.stmikjayakarta.ac.id/index.php/jisicom/article/view/363

[17] Verdi Yasin, Azhar Ahmad Riza, Rumadi Hartawan (2017) "Pengembangan Aplikasi Pemulihan Layanan Bencana Sistem Informasi Peneriman Negara Bukan Pajak Online Di Lingkungan Kementerian Keuangan Republik Indonesia”, Journal of Information System, Informatics and Computing. EISSN: 2597-3673 (Online), P-ISSN: 2579-5201 (Print) Vol. 1 No. 1, September 20, 2017. Pp.33-56. http://journal.stmikjayakarta.ac.id/index.php/jisicom/article/view/4

[18] Verdi Yasin (2021) "Penerapan sistem kegiatan belajar dan mengajar dalam instrumen Sertifikasi Dosen Profesional menggunakan metode SMART”, Tridharmadimas: Jurnal Pengabdian Kepada Masyarakat Jayakarta,E-ISSN: 2798-8295 (Online), P-ISSN: 2798-8554 (Print) page: 37-55 DOI: 10.52362/tridharmadimas.v1i1.501 URL: http://journal.stmikjayakarta.ac.id/index.php/tridharmadimas/article/view/501 